\title{
Energy Auditing and Improvement Scheme for Faculty of Applied Medical Sciences at Taibah University
}

\author{
Khaled S. AlQdah*, Osama Alhazmi, Mustafa Mohammad, Abdulelah Alzahrani, Hussein Alaqeel \\ Mechanical Engineering Department, College of Engineering, Taibah University, Medina, KSA \\ Email: *kqdah@taibahu.edu.sa, *dr.khaled_qdah@yahoo.com
}

How to cite this paper: AlQdah, K.S., Alhazmi, O., Mohammad, M., Alzahrani, A. and Alaqeel, H. (2020) Energy Auditing and Improvement Scheme for Faculty of Applied Medical Sciences at Taibah University. Open Journal of Energy Efficiency, 9, 64-80.

https://doi.org/10.4236/ojee.2020.91005

Received: November 4, 2019

Accepted: March 20, 2020

Published: March 23, 2020

Copyright ( 2020 by author(s) and Scientific Research Publishing Inc. This work is licensed under the Creative Commons Attribution-NonCommercial International License (CC BY-NC 4.0).

http://creativecommons.org/licenses/by-nc/4.0/

\begin{abstract}
In this work, a survey is used to investigate the current energy performance for Faculty of Applied Medical Sciences (previously Faculty of Engineering) at Taibah University in Medina city. The results of the survey show that several factors affect the energy performance in this building. It revealed that the building has been poorly designed from the point of view of thermal performance. Therefore, the building energy consumption needs to be monitored and maintained through energy auditing program. To determine the energy profile, the power consumption was calculated; the cooling load was estimated and analyzed to know the actual capacity required. The level of comfort in the building has been evaluated. Against the installed air conditioning capacity of 200-ton refrigeration, the cooling load calculations showed that the maximum cooling load needed, which is in August is only 83.22-ton refrigeration. In addition, illumination levels were measured and compared to the standard levels. Based on obtained results, two solutions were proposed: to install a building management system with approximate cost of 337,904 SR and to replace the existing chiller. Finally, the payback period for the proposed system has been estimated and found to be about 5.4 years.
\end{abstract}

\section{Keywords}

Auditing, Payback Period, Cooling Load, Building Management System, Illumination

\section{Introduction}

Energy audit is considered as an essential method to evaluate the energy usage and wastage in buildings. Also, it can be considered as an efficient process to 
evaluate the energy efficiency of a house by using certain devices. Saudi Arabia is one of the highest energy consumption countries in the world as shown in Figure 1 [1]. From this figure, the total energy consumption in 2018 is about 290 million MWh. The reason behind that is the fast growth in population, the development that the country witnessed during the last five years and the high quality services offered by the government to the population. The weather is always warm in most of the cities in Saudi Arabia, which means the air conditioner is always on. Therefore, more than $70 \%$ of its electricity used to run the air conditioning and cooling systems [2]. The average power consumption in one of the summer period months is equal to three times the average power consumption in one of the winter period months; another $20 \%$ of Saudi Arabia's electricity is used to desalinate sea water for drinking. About $60 \%$ of the water people use in their homes comes from the country's 30 desalination plants [2]. Most of Saudi Arabia's electricity is generated by burning fossil fuels where 59\% from oil and 41\% from natural gas [3]. In April 2016, Saudi Arabia government implemented and deployed the Saudi 2030 Vision. This vision focused on developing the kingdom cities and achieving environmental sustainability by enhancing the buildings energy performance and energy consumption. Also, one of main aims of this study is to focus the efforts towards the renewable energy resources to replace the dependency on the conventional energy resources [4].

In this work, the team aims to conduct an energy auditing program for the building No. 115 which is used as the main building for faculty of applied medical sciences (previously Faculty of Engineering) at Taibah University. This will enhance the building energy performance to satisfy the human comfort. Also, this building represents an example that satisfies all the engineering principles that have been learnt toward other people and the environment. The scope of the work is to reduce the energy consumption, to prove how much the university could lower the energy expenses and to implement this experience to other buildings in the University. A lot of energy auditing studies were conducted by many researchers. V. Shcherbak et al., 2019 [5] developed a comprehensive energy auditing program to assess 15 University buildings by 16 performance indicators to identify the main terms of energy consumption and energy efficiency.

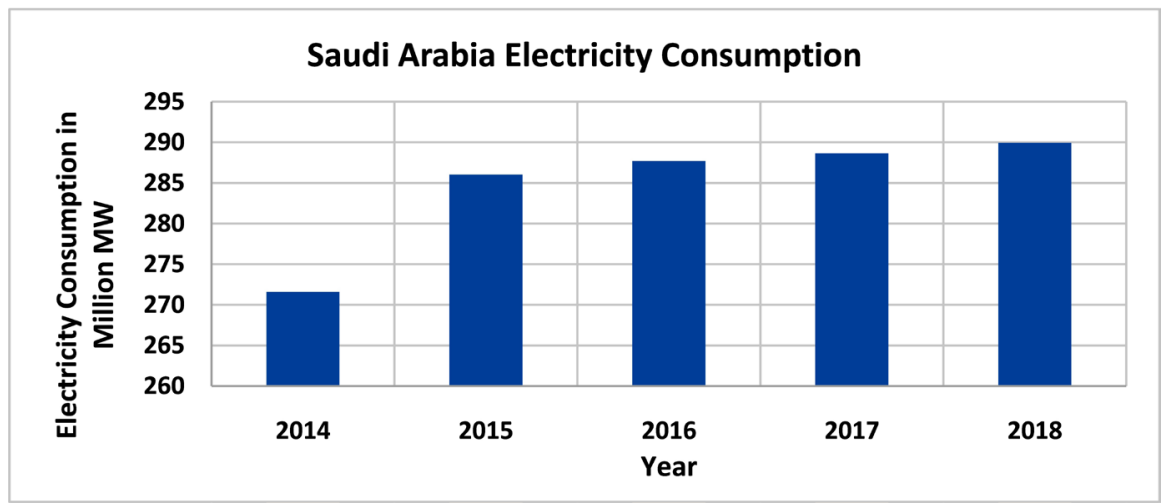

Figure 1. Electricity consumption in Saudi Arabia in last 5 years. 
Ali Alajmi, 2012 [6] found out an energy conservation opportunity of an educational building in Kuwait state by a walk-through assessment, survey and data analysis. Economic analysis of the findings was conducted and the reported result showed an acceptable pay-back period. V. Corradoa et al., 2017 [7] presented a basic step toward the net energy zero building (NZEB) target for high school in Torino. Detailed energy audit has been conducted by using a numerical model of the building. Their measurement was improved to comply with the NZEB requirements and to be cost-effective as well. Lu Lia et al., 2017 [8] analyzed the energy saving potential for one university of Guangzhou by using a survey of the end-use energy of various premises in the college. They proposed some effective measures enhance the energy efficiency in the building. A. Magrinia et al., 2016 [9] discussed the energy saving scenarios for University of Pavia. The energy audit of the whole University buildings has been applied to outline and overview of potential energy consumption reduction as well as energy cost. $\mathrm{K}$. Al Qdah, 2010 [10] investigated the potential of energy savings in a Jordanian poultry company. All the mechanical equipment was reviewed such as boilers, air compressors, refrigeration units and pumps. It was found that many opportunities to save energy with a reasonable payback period. Kholoud M. Hassouneh, et al. 2014 [11] conducted energy audit for one department at the faculty of engineering and technology at the University of Jordan. They studied the energy savings techniques, heating and cooling loads were estimated in addition to lights load and other equipment. The estimated payback period found to be 3 years. Mohamad I. Al-Widyan, et al. 2018 [12] investigated the building performance through an energy auditing program including the air conditioning system, lighting systems and building envelope using necessary and standard measurement tools. They offered a proposed retrofit solution that can save 33\% from the annual energy consumed by the building. Fayad Abdallah Mohamed Ahmed, 2017 [13] performed an energy auditing program, measurements were conducted for three school buildings, the results for the three schools were analyzed economically for lights, ventilation and buildings insulation. The proposed recommendations to enhance the building performance will save $120,737 \mathrm{kWh} /$ year for heating and $21,962 \mathrm{kWh} /$ year for the electricity consumption with payback period of 4.2 years. Al-Ghandoor, A. and Al-Hinti, I., 2007 [14] carried out an energy auditing investigation for the opportunities of electrical energy savings in the Jordanian plastic industry. They recommended a program that will save $23 \%$ of the total plastic industry electricity bill with a payback period of less than 7 months. Kholoud M. Hassouneh et al., 2017 [15] carried out energy auditing program of the University of Jordan Hospital, the energy audit covers the emergency clinics and the main hospital buildings. A feasibility study shows that the energy auditing and the proposed solutions would be very useful and will save $12.5 \%$ of the energy bill. Cho et al. [16] [17] analyzed the characteristics and performance of the HVAC systems of the hospital building in the aspect of combined concept that focused on the system configuration and climate characteristics. The energy effect accord- 
ing to the FCU (fan coil unit) +DOAS (dedicated outdoor air system), and CAV (constant air volume) and VAV (variable air volume) systems were analyzed. They derived a simulation-based methodology that can analyze the energy consumption effect according to the components of the HVAC system of the hospital building. Ma et al. [18] analyzed the energy consumptions and characteristics of 119 public buildings located in north China. The results showed that among the offices, hospitals, and schools, the hospitals were using the energy more than two times, and it was evaluated that the HVAC, lighting density, and building envelope had the largest effect on the energy consumption. In November 2010, the KSA government introduced the Saudi Energy Efficiency Center (SEEC) and, in March 2018, it started functioning after the Saudi 2030 Vision announcement [19]. Approximately $40 \%$ of the emission reduction required by 2050 to limit global temperature increase to less than $2^{\circ} \mathrm{C}$ would potentially come from energy efficiency [20]. From the previous studies it can be seen that numerous efforts to investigate the prospects of energy saving and many scenarios were reported and many solutions proposed to reduce energy consumption in the education buildings. Few work has been done to evaluate the colleges or universities energy consumption, in the kingdom of Saudi Arabia, this can be considered as a motivation for this work to enhance the students, faculty members and other staff awareness towards energy saving and its impact on the society.

\section{Methodology}

\subsection{Survey}

In the energy audit projects, one of the most significant parameters is taking the people comfort and satisfaction in the consideration before starting. Survey is the process of gathering information about specified issue through randomly chosen intended people to know their opinions about that issue. A questionnaire was distributed among 52 of the building visitors as an assessment sheet of the comfort satisfaction level. The questionnaire asked about the period of time which the member of the faculty spends in the building and we divided the responses into four options: 1 - 3 hours, 4 - 6 hours, 7 - 9 hours, and more than 9 hours. Figure 2 below illustrates results of this part. After that, the questioner started to ask them about the air conditioning system and evaluation of the temperature comfort level. The options were: Too cold, cold, and satisfying. The results of this question illustrated as shown in Figure 3. One important parameter that concludes from this figure is that most of the members who chose the option too cold means the air conditioning system does not work well and over cooling problem is taking place in the building.

Another factor to feel comfortable is the air refreshed supplied to the building, the survey asked some of the faculty members and other staff about the availability of fresh air. The result was as shown in Figure 4 . The level of the humidity is also significant property to feel comfortable and satisfied the conditioning 
system at any building. The result of this questionnaire is illustrated in Figure 5 below.

Eventually, the questioner asked about the overall the comfort satisfaction in the faculty building and the result was shown in Figure 6 below.

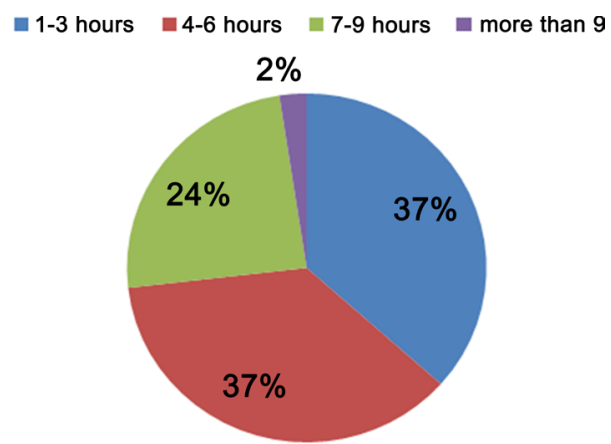

Figure 2. Percentage of working hours in the offices.

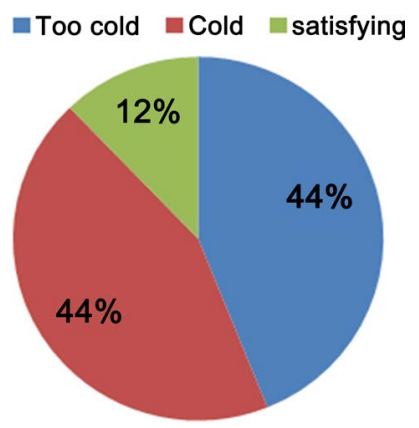

Figure 3. Air conditioning performance evaluation.

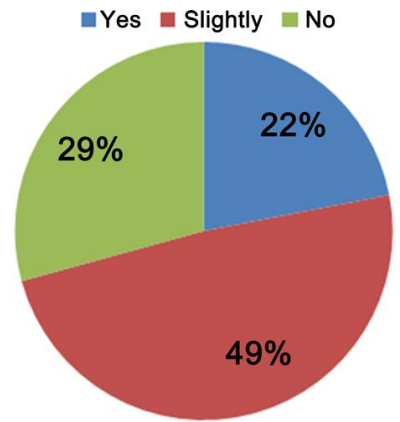

Figure 4. Percentage of fresh air satisfaction.

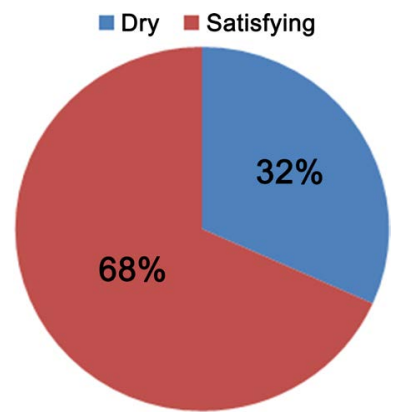

Figure 5. Percentage of humidity satisfaction. 
From the above figures it can be seen that the number of working hours about 8 hours a day and the air conditioning performance is not satisfied (cooled) but the fresh air is slightly satisfied. Only lighting level and humidity level satisfied which mean the building human comfort not exactly satisfied and intensive work need to be conducted to enhance the building performance.

\subsection{Building Analysis}

All data and information about the faculty of applied medical sciences building have to be collected and analyzed. Two types of plans should be collected: construction Plan (As Built Drawings) and air conditioning plan. The main aims of using the construction plan is to identify the building's basic components and materials used because of its impact on the nature of the lighting used and to facilitate the calculation of cooling loads and to know the availability of good ventilation in the building to achieve the desired human comfort. As for the use of the air conditioning and refrigeration plan, it helps in understanding the air conditioning system that is already existing in the building and identifies what are the defects in this system and technical problems that reduce its performance and the possibility of finding solutions to it.

\subsubsection{Building Envelope and Dimensions}

Figure 7 below shows the building ground floor envelope and dimensions in millimeter in 3D model that was produced by Auto CAD program.

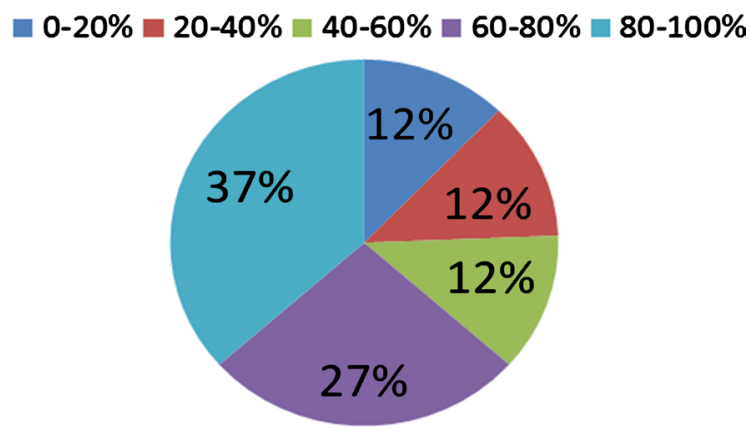

Figure 6. Percentage of overall comfort satisfaction in the building.

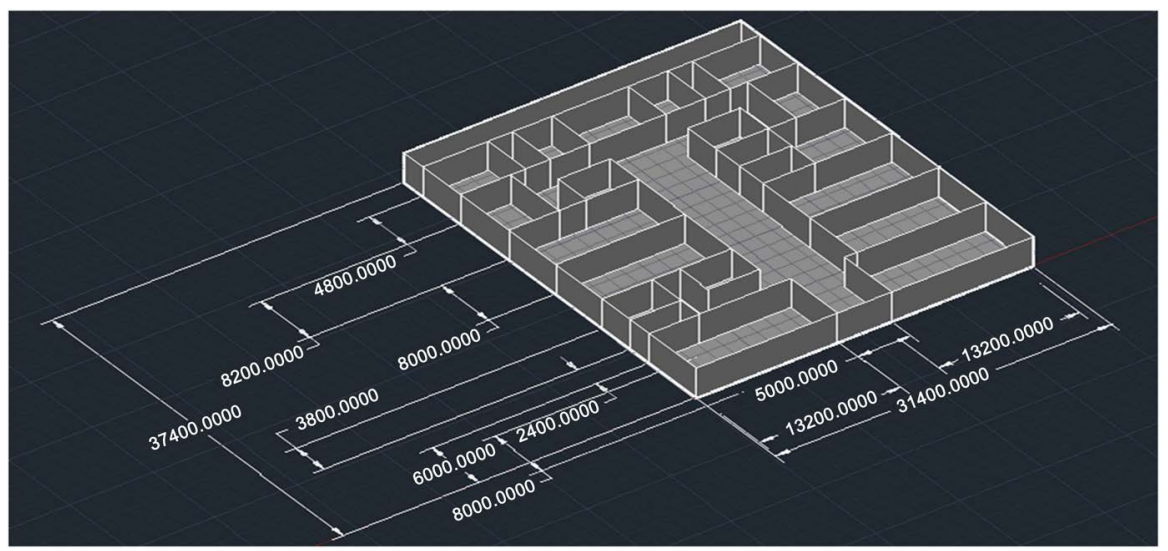

Figure 7. Ground floor in 3D model. 


\subsubsection{Wall Structure}

Two types of walls are used in the building. The first type is used in the partitions between each room inside the college and the other type used in external sides. The wall material is concrete with $200-\mathrm{mm}$ thickness; the other is the external wall. Table 1 shows all specification of the walls as well as dimensions. This table can be used to find out overall heat transfer coefficient or U values for the building.

\subsection{Air Conditioning System}

\subsubsection{Air Conditioning System Specifications}

The faculty building installed two different packaged systems. The two specific Carrier and Al-Zamil packaged systems that installed at this building have a maximum volt of $380 \mathrm{~V}$ for each unit, two compressors, two outdoor and one indoor fans. Table 2 shows the detailed specifications for the two systems.

\subsubsection{Cooling Load}

Calculating the cooling loads is an important factor in determining the capacity of the air conditioner that can be used efficiently in the building. All specifications and characteristics of the materials used in building and constructing of this building in addition to the dimensions and thickness of the walls, ceiling and glass were obtained from the contractor who built and implemented construction and mechanical works of this building. HAP (Hourly Analysis Program) is used to estimate the building cooling load. This program has the ability to calculate all the cooling load after providing all data, specifications, dimensions and materials used in the building construction. Figure 8 and Figure 9 show the maximum cooling load in January and August. The maximum cooling load occurs at 02:00 PM.

Table 1. Details of walls specifications and thickness.

\begin{tabular}{cccc}
\hline Type & Thickness & Material & $\mathrm{K}(\mathrm{W} / \mathrm{m} \cdot \mathrm{K})$ \\
\hline Partition & $200 \mathrm{~mm}$ & Concrete & 0.72 \\
External walls & $100 \mathrm{~mm}$ & Concrete block & 0.35 \\
External walls & $50 \mathrm{~mm}$ & Polystyrene & 0.034 \\
External walls & $200 \mathrm{~mm}$ & Concrete & 0.72 \\
External walls & $30 \mathrm{~mm}$ & Concrete plaster & 0.72 \\
External walls & $50 \mathrm{~mm}$ & Marble & 2.07 \\
\hline
\end{tabular}

Table 2. Specification of the current HVAC systems installed in the building.

\begin{tabular}{ccccccc}
\hline $\begin{array}{c}\text { Model } \\
\text { Number }\end{array}$ & $\begin{array}{c}\text { No. of } \\
\text { units }\end{array}$ & $\begin{array}{c}\text { Total Cooling } \\
\text { Capacity }\end{array}$ & Max. Volts & Compressors & No. of Fans & Refrigerant \\
\hline $\begin{array}{c}\text { ZAMIL-AC } \\
\text { PMX360 }\end{array}$ & 2 & 80 TR each & $380 \mathrm{~V}$ & 2 Reciprocating & $\begin{array}{c}2 \text { outdoor, } \\
1 \text { indoor }\end{array}$ & R-22 \\
\hline $\begin{array}{c}\text { CARRIER } \\
\text { 50TJ-032-231S }\end{array}$ & 2 & 20 TR each & $380 \mathrm{~V}$ & 2 scroll & $\begin{array}{c}2 \text { outdoor, } \\
1 \text { indoor }\end{array}$ & R-22 \\
\hline
\end{tabular}




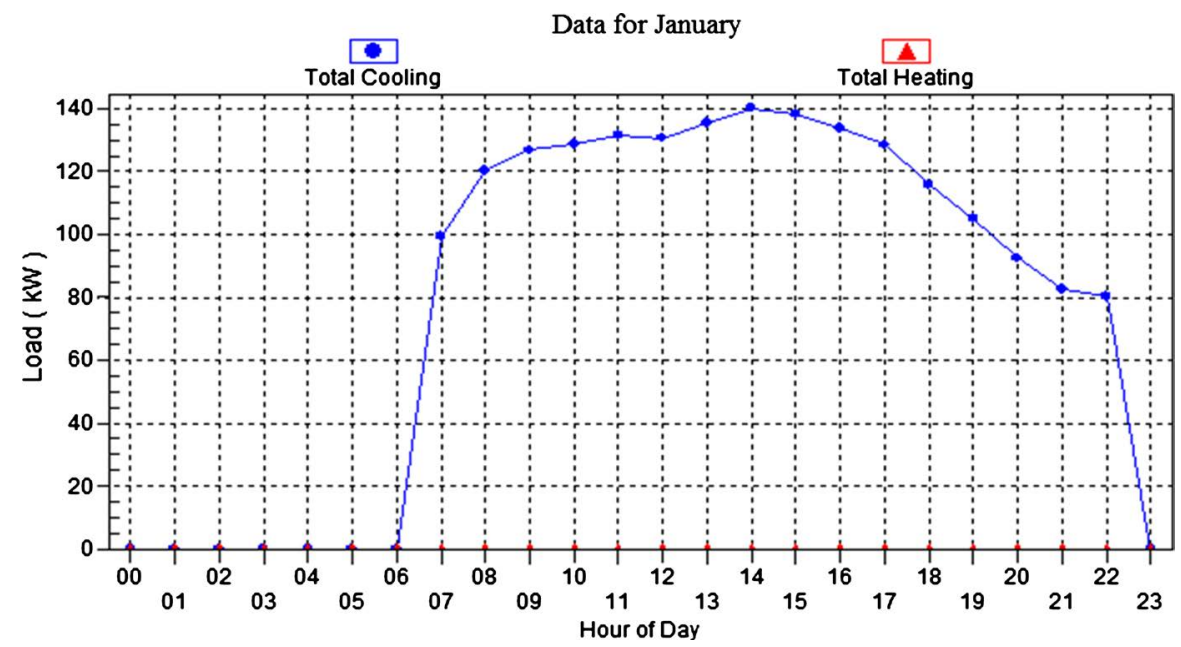

Figure 8. Hourly cooling load for January.

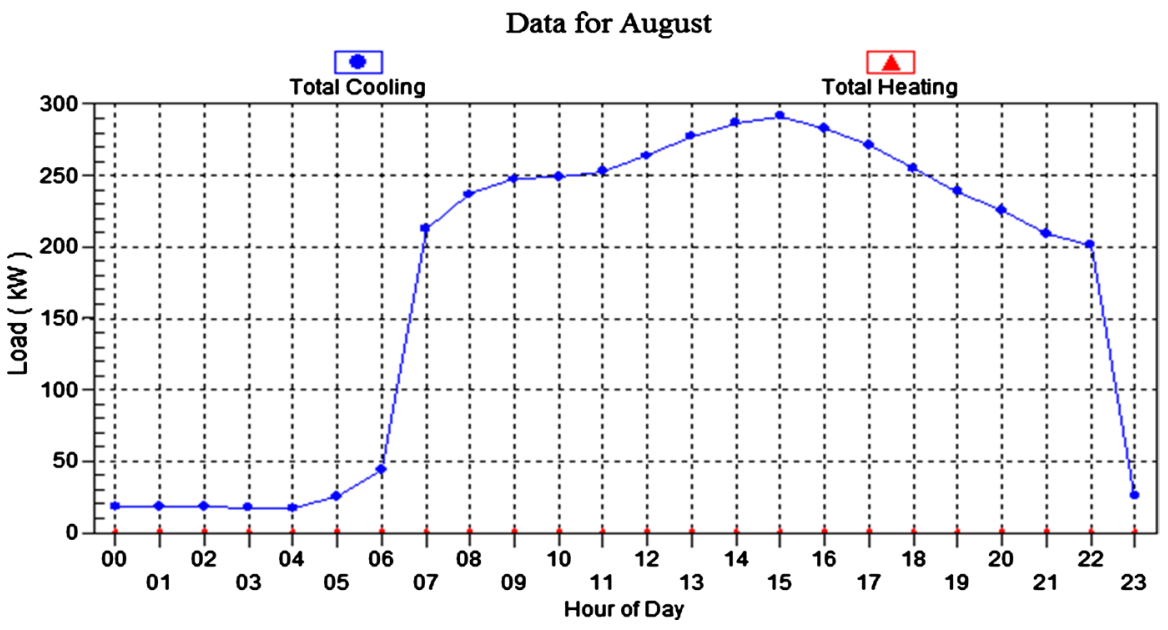

Figure 9. Hourly cooling load for August.

Because the building electricity supply stops at 11:00 PM, the cooling load is set to zero up to 06:00 AM. In order to show the differences between the months, the following figure shows hourly cooling load for August. As shown in Figure 9, the maximum load occurs at 03:00 PM, which is different from the January maximum load that occurs at 05:00 PM. In addition, the maximum value in August is 292.7 $\mathrm{kW}$ or $83.22 \mathrm{Ton}$, which is the maximum in the whole year and it is greater than January maximum value.

\subsection{Illumination}

Illumination is a very important factor in energy consumption of any building. Especially, in energy auditing. A lux meter can be used to measure the lighting intensity in all rooms, halls, entrances, etc. The model that used in this investigation is the ILM-01 which is manufactured in England by ISO-TECH as shown in Figure 10.

The recommended standard illumination levels to human eye comfort set by many organizations, the standard comfort level used in Germany in regular of- 
fices where usual activities are reading or PC work is $600 \mathrm{~lx}, 750 \mathrm{~lx}$ in laboratories where there is detailed work and $750 \mathrm{~lx}$ in hallways [21].

The luminance measurements that are taken in this auditing project are in lux. The measurements were carried-out using the mentioned above ILM-01 lux meter in every room. Table 3 illustrates the average of luminance in each room with six to eight measurements taken for the laboratories and two to three taken for offices depending on their size and occupants.

\subsection{Power Consumption Analysis}

The building is used as educational building that works about 8 hours daily, 300 days a year. Usually this type of buildings is two times more energy-intensive than other government buildings. Therefore, it is extremely necessary to investigate the total energy consumption.

One of the design faults of the building is that it has no stand-alone electricity unit with watts' meter. The faculty of applied medical sciences is electrically connected with the medical center and the deanships circular building. As a result, the electricity bills are issued for the three buildings all together as one building

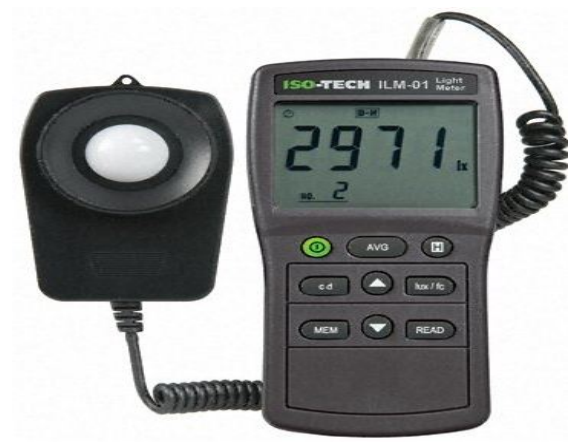

Figure 10. Lux meter model ILM-01 that used in this investigation.

Table 3. luminance measurements taken for the building.

\begin{tabular}{|c|c|c|c|c|c|}
\hline Location & $\begin{array}{l}\text { illumination } \\
\text { levels (in lx) }\end{array}$ & Location & $\begin{array}{l}\text { illumination } \\
\text { levels (in lx) }\end{array}$ & Location & $\begin{array}{l}\text { illumination } \\
\text { levels (in } 1 \mathrm{x} \text { ) }\end{array}$ \\
\hline Power Lab & 778 & G-17 & 689.5 & Corridor & 413 \\
\hline Fluid Lab & 823.8 & G-20 & 653.7 & West Stairway & 147 \\
\hline Computer Lab & 906 & G-27 & 395 & East Stairway & 144 \\
\hline Electronic lab & 769.7 & $\begin{array}{c}\text { Hallway Nearby } \\
\text { the entrance }\end{array}$ & 689.5 & $\begin{array}{l}\text { Dean's office } \\
\text { Manager }\end{array}$ & 679 \\
\hline Dynamics Lab & 695.3 & $\begin{array}{l}\text { Hallway near } \\
\text { the offices }\end{array}$ & 589.66 & Secretary office & 358 \\
\hline Circuit lab & 853.4 & $\begin{array}{l}\text { Hallway leading } \\
\text { to room G-20 }\end{array}$ & 575.25 & Dean's Office & 855 \\
\hline G-12 & 974.6 & Printing room & 433 & F03 & 494 \\
\hline G-13 & 703 & F-25 & 471 & F14 & 603 \\
\hline G-14 & 651.3 & F-30 & 743 & East Toilet & 363.5 \\
\hline
\end{tabular}


and there is no electricity bill for the faculty building alone. So, the electricity bills can't be used for analysis. To overcome this problem, a power analyzer must be used in the electricity breaker that is specified for the engineering building only. Upon the readings from the power analyzer, a power-time curve shown in Figure 11 has been generated to find the peak power demand at peak time.

\section{Auditing Results}

The purpose of any energy auditing is to report all the resources where energy is being wasted. In addition, it is also important for the building to reflect the concepts of engineering by optimizing all the energy resources fed into it. For example, the capacity of an HVAC system must be chosen improperly because it might be more than what is needed actually. Another example, the intensity of light might be distributed incorrectly. Therefore, many aspects of the building must be inspected, analyzed and optimized. Inspection will be conducted by proper cooling load calculations, intensity of light and chances to decrease the waste energy resources and maintaining the systems efficiency and output.

From Table 2, it can be seen that the offices lie in the ground floor, the wasting energy exceeding the standard level of $600 \mathrm{~lx}$. Only office G-27 where illumination level is below the healthy level and it should be increased. For the hall area of the building, it can be divided into two areas, hallways and the middle area of the hall with the high ceiling. The hallways have a lower ceiling with lights that are operated during the daylight, On the contrary of the area with the high ceiling where lights are turned on automatically in the evening only. There are two hallways in the ground floor, one is by the entrance and the other is the inside one by the faculty members' offices. It is not reasonable to take the average of the two hallways because the one nearby the entrance is mostly illuminated by the sunlight.

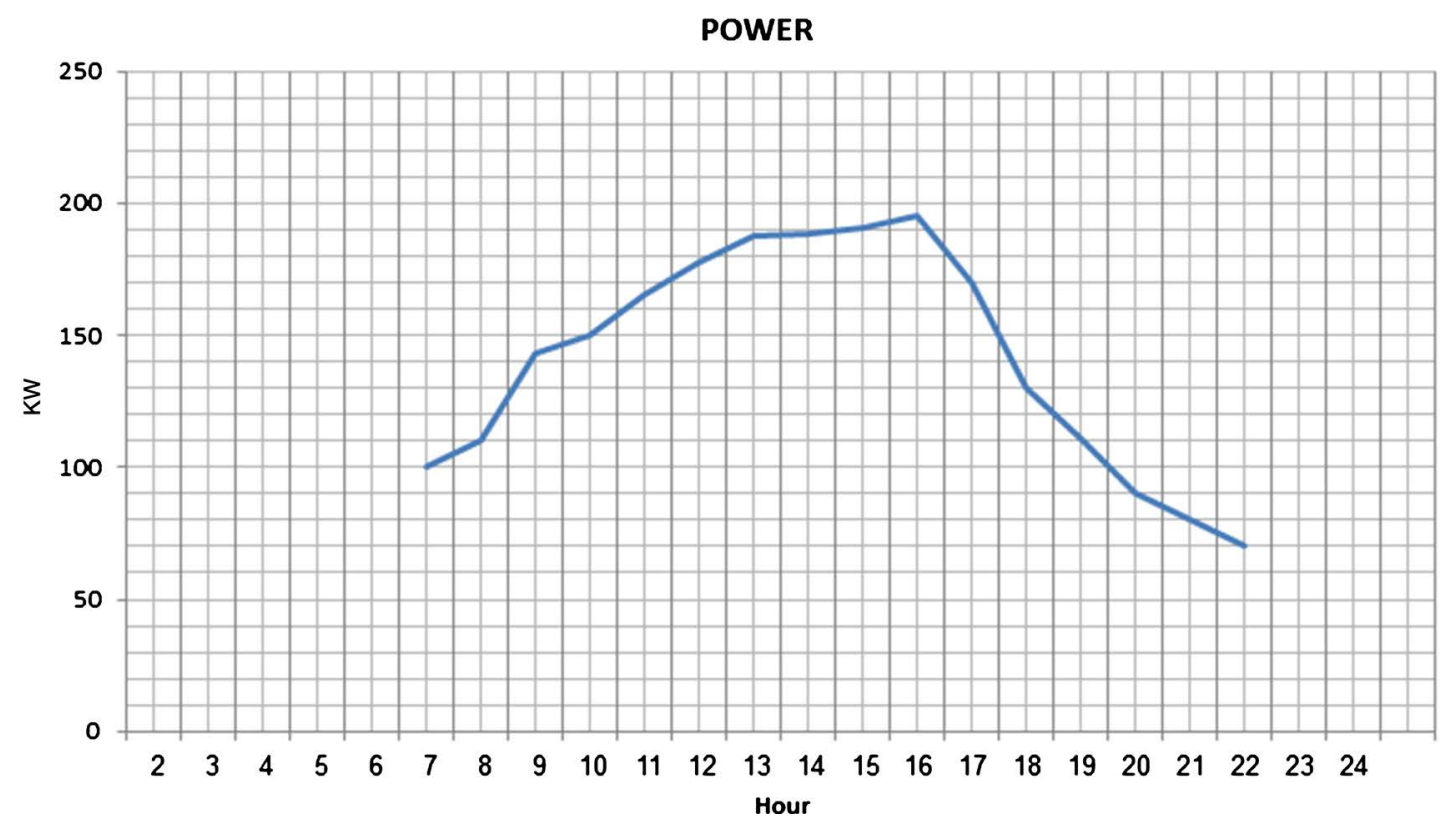

Figure 11. Power Profile generated for the building using specific power analyzer. 
It is obvious that the hallway area in front of the entrance door has high illumination from the sun, while the lighting in front of the entrance is turned on during the daylight leading to useless wastages of energy. On the other hand, the two hallways nearby the faculty members' offices and the hallway leading to room G-20 are almost close to the standard level of $750 \mathrm{~lx}$. The hall area in the middle of the building has lights which are disabled. For the second floor, the averages of each room in lux, where 6 - 10 readings were taken for large rooms (e.g. dean's office), 3 - 5 for small rooms (e.g. teaching assistance offices). Total excessive lux in the second floor equals to

$$
\sum \text { (room illumination level - standard level) }
$$

Applying this formula, the excessive lux $=2260.8$ lux. Using the same formula, the excessive lux of the first floor is calculated to be $=354.9$ lux and the total excessive lux for the whole building $2260.8+354.9=2615.2$ lux.

Using the sun effect factor as 0.355 [18], the sun effect on readings has been determined by comparing readings during the day with readings of the same place after sunset. Therefore, the total excessive lux will be $2615.2 \times 0.355=928.3$ lux.

To get the power consumption of the excessive lighting, the following formula is used to convert lux to Watts:

$$
P=\frac{E v(\mathrm{~lx}) \cdot(A / 2)}{\eta} \quad[23]
$$

Using online converter [18], the excessive power $=9.081 \mathrm{~kW}$, where the efficiency of fluorescent lamps $\eta=0.6$.

$$
\begin{aligned}
\text { Cost } & =\text { Power }(\mathrm{kW}) \cdot \operatorname{Price}(\mathrm{kWh}) \cdot \text { working hrs } \\
& =9.081 \times 0.26 \times 9=21.24 \mathrm{SR} \cdot \text { daily } \\
& =637 \text { monthly and } 7752.6 \mathrm{SR} \cdot \text { annually }
\end{aligned}
$$

One important parameter that concluded from the survey indicates that most of the members who chose the option too cold means that the air conditioning system does not working exactly or efficiently and over cooling problem is taking place in the building. Thus, the air conditioning system must be reviewed and solved. Figure 11 illustrated the power profile for the building. From this figure, it is clear that the load reaches its peak value at 4:00 PM. This figure had to be integrated to find the power in kWh and multiply it by the price obtained from the electricity company which is $0.26 \mathrm{SR} / \mathrm{kWh}$. The integral of the graph is 2222.7 $\mathrm{kWh}$ and the cost $577.9 \mathrm{SR}$. The current HVAC consumes $1830 \mathrm{kWh}$, which is almost $83 \%$ of the total consumption. 1830 with approximate cost of $475.8 \mathrm{SR}$.

\section{Improvement Scheme}

Minimizing the energy waste is of great importance to maintain the security of energy supply. The following recommendations were suggested to enhance the building energy performance: 


\subsection{Building Management System}

BMS (Building Management Systems) is a system that can be used in a building to control and monitor its mechanical and electrical equipment operation. This system usually connected with advanced central computer [21] to record and analyze the energy consumption for long time. It can also control the illumination system by detecting whether there are employees in the room or not, and upon that, the computer will switch the lights to On/Off automatically.

BMS is also capable of controlling $\mathrm{CO}_{2}$ levels, air conditioning dampers that are connected to the system. Furthermore, it can detect fire and smoke. In spite of higher initial cost, building management system is a promising energy saving sources, good environmental impact, failures reporting directly to the technical, high security tool and equipment life becomes high [21].

\subsection{BMS Design for Building 115 (College of Applied Science)}

\subsubsection{BMS Block-Diagram and Process Sequence}

Each system has its components that in whole make it a full system capable of delivering the desired output. The integration between these components must be done in a way that assures no conflicts and smooth running. The BMS designed for the building under investigation is to control the air conditioning and lighting systems. The following block-diagrams shown in Figure 12 and Figure 13 will make it easier to understand how they integrated. To illustrate the sequence of the process a flow-chart was made for the HVAC and lighting system, separately. Figure 12 demonstrates the flow-chart of the HVAC system.

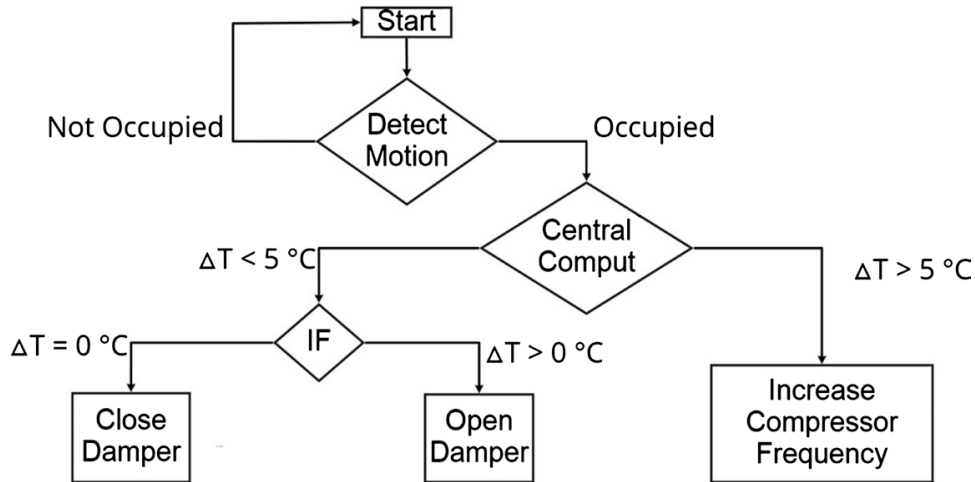

Figure 12. HVAC flow chart.

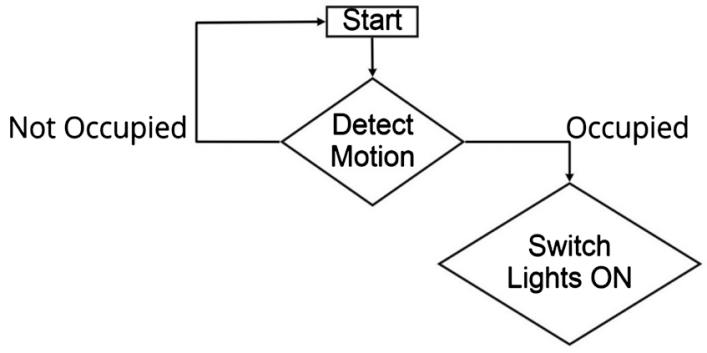

Figure 13. Lighting system flow-chart. 
The motion sensors will give the central computer (CC) readings whether there is someone inside the room or not. Central computer will take feedback from temperature sensor and upon $\Delta \mathrm{T}$ it will determine whether to run the air conditioning system or not by open or closed the damper. Figure 13 illustrates the process sequence of how the lighting system being control. The lighting flow-chart will also depend on the motion sensor, if the detector senses motion lights will be turned $\mathrm{ON}$ otherwise lights will remain turned off.

\subsubsection{Installing New Chiller}

Chiller is the most significant part in the cooling system, therefore, it should be chosen according to the precise criteria to come up with efficient cooling system with suitable cost [23]. For the applied science college building, the expected type of chiller is air cooled chiller, that exchanges heat with air, with scroll compressor. This type of chillers will be efficient and give the cooling capacity required for the building. The cooling capacity which is required for the college building is $83.7 \mathrm{TR}$ (Ton Refrigerator) [24] and it is equal to $294.4 \mathrm{~kW}$ (as 1-ton refrigeration equals to $3.516 \mathrm{~kW}$ ).

The chosen model is the air cooled liquid chiller with a variable frequency scroll compressor is (YLAA 180 to $515 \mathrm{~kW}$ ). YLAA air-cooled chillers are completely factory assembled with all interconnecting refrigerant piping and wiring ready for field installation. The chosen one amount the four versions is YLAA-HE because of its high efficiency rather than the standard efficiency, and the low sound model is not needed because the current ones installed are not low sound versions and yet, the noise is not heard from the inside.

The model number of the chiller changes according to the variation in the cooling capacity that the chiller provides. So, the model can give the cooling capacity needs is YLAA0156HE40. This chillier will give 119.6 TR as a cooling capacity using R410A as refrigerant [24]. The cost of this chiller is 320,000SR and the expected input power for the new chiller is shown in Figure 14.

From Figure 14, the integral of the graph was calculated to give $1165 \mathrm{kWh}$, which gives: $1165 \times 0.26=302.9$ SR .

\subsubsection{BMS Sensors}

Sensors are one of the most effective components in designing a building management system (BMS). The sensors will send these data to the Central Computer to display it and/or usually in BMS take an action. Faculty of Applied Science College building has two floors classified to two major's kinds depends on the work's hours. These two types are clearly shown in Figure 15. The rooms with numbered in 1 for the faculty members who have no fixed work hours and rooms which are numbered in 2 is pointing to employees' offices whom have a fixed work hours start at 8:00 am and finishes at 2:15 pm.

The rooms with the unfixed work hours (numbered 1) will be mounted with motion detectors, where the rooms with the fixed work hours will have the ON/OFF system starting nearly 7:30 AM and shutdown at 2:30 PM. and for the lightings system, lights will be switched $\mathrm{ON}$ automatically from 8:00 to 2:20. 


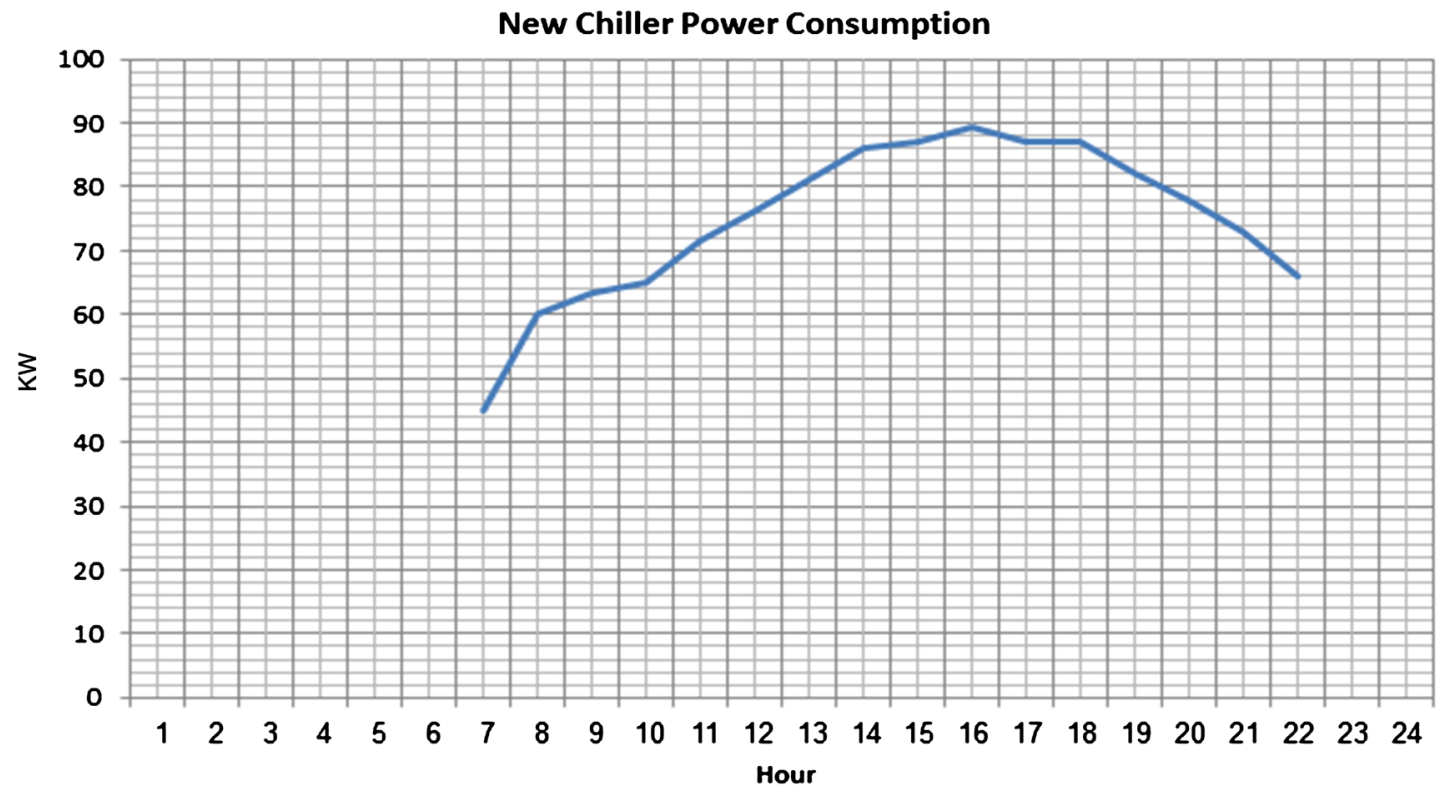

Figure 14. Power consumption of the new chiller.

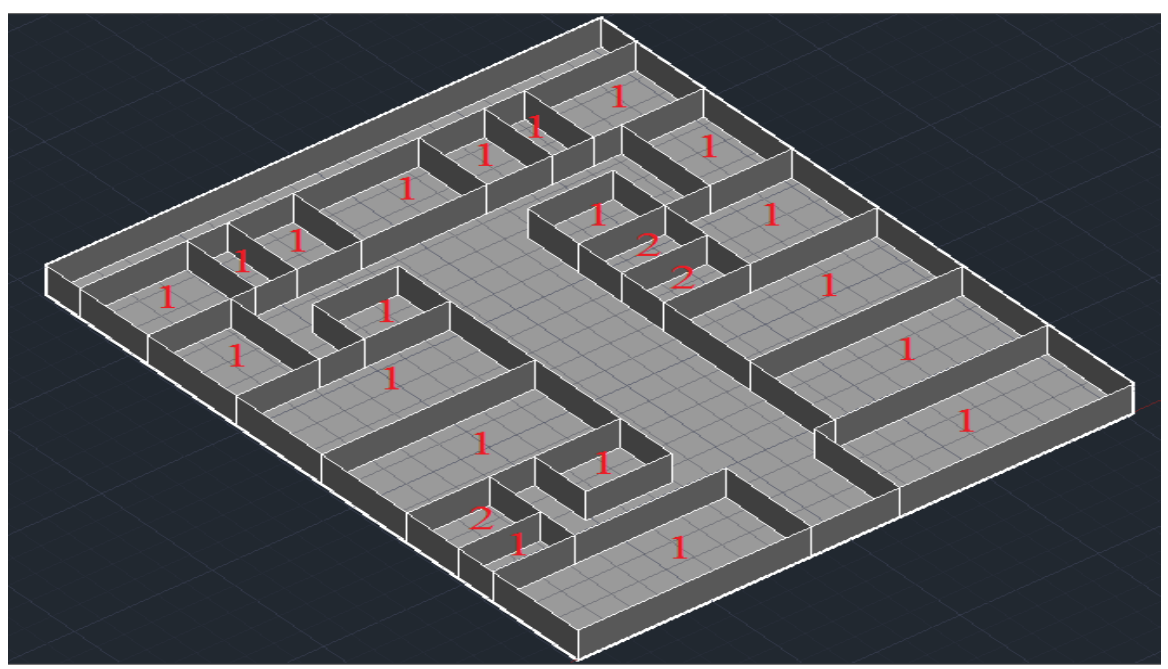

Figure 15. Suggested sensors location for the building.

\subsubsection{Sizing and Selection of Motion Detectors}

The rooms that will be sensed by the motion detectors classified into three major sizes. The labs have two sizes $13 \times 6 \mathrm{~m}^{2}$ and $12 \times 6 \mathrm{~m}^{2}$ and the dean's offices have the size of $7 \times 6 \mathrm{~m}^{2}$ where the faculty members (professors and TAs) offices have the size of $4 \times 3 \mathrm{~m}^{2}$.

Selection of the sensors is depending on several features, such as detection range (angle and distance), power supply, sensitivity, and cost. As we mention the college building has three different room sizes according to that, three different detectors will be used. Compiling between the features of the motion detectors and the sizes of the rooms will lead the system designers to select the most proper detectors to be mounted into the rooms. Table 4 below show the features of the detectors according to the room size and how many detectors needed in the building. 
Table 4. Motion detector quantity and price.

\begin{tabular}{cccccc}
\hline Room Type & $\begin{array}{c}\text { No. of } \\
\text { Rooms }\end{array}$ & Size in $\mathbf{m}^{2}$ & $\begin{array}{c}\text { Detectors Quantity } \\
\text { per Room }\end{array}$ & Detector Range & $\begin{array}{c}\text { Price per } \\
\text { piece in } \$\end{array}$ \\
\hline Lab type 1 & 2 & $13 \times 6$ & 1 & $360^{\circ} \times 12.2 \mathrm{~m}$ & $\$ 68$ \\
Lab type 2 & 4 & $12 \times 6$ & 1 & $360^{\circ} \times 12.2 \mathrm{~m}$ & $\$ 68$ \\
Deans offices & 3 & $7 \times 6$ & 1 & $88^{\circ} \times 18 \mathrm{~m}$ & $\$ 22.85$ \\
F. M. office & 9 & $4 \times 3$ & 1 & $360^{\circ} \times 7.3 \mathrm{~m}$ & $\$ 33$ \\
\hline
\end{tabular}

The costs of all items which are needed to accomplish the building management system for the engineering faculty building is $337,904 \mathrm{SR}$.

\subsection{Automatic Door}

One of the biggest causes of energy wasting in the applied science college building is the main door when it is left opened for no reasons. As a consequence, cold air inside is lost which increases the load on the HVAC. Also due to the government regulations, it is prohibited to install dampers on doors of government buildings as this will make it difficult for people with disabilities to use it. So, the best way of resolving this issue is to install an automatic door with motion sensor. For the size of the entrance, an automatic door will cost around 2800 SR.

\subsection{Economical Analysis}

The payback period of the suggested solution is calculated using the breakeven analysis. The breakeven analysis is an approach to determine the point where the investment and revenue are equal, which is the payback period.

$$
\begin{gathered}
\text { Payback Period }=\text { Total Cost } / \text { Total Saving per day } \\
\text { Payback Period }=337,904 /(475.8-302.9)=1955 \text { day }=5.4 \text { years }
\end{gathered}
$$

where: $337,904 \mathrm{SR}$ is the total cost of the system, $475.8 \mathrm{SR}$ is the current HVAC payment every day and 302.9 is the new chiller expected payment every day.

\section{Conclusion}

This study aimed to assess how the energy performance of college buildings at Taibah University in Medina. Energy auditing for the faculty of applied medical sciences building showed that the installed capacity of the HVAC system is 200 Tons while cooling load calculations showed that the maximum cooling load needed in August only 83.22 Tons. Also, the illuminations for most of the rooms are above the standard levels by $928.3 \mathrm{~lx}$ which costs 21.24 SR every day. All that together, the building consumes $2222.7 \mathrm{KWh}$ daily which costs 577.9 SAR. For that reason, a well-developed energy management system in the building can help to reduce excessive energy consumption. A building management system has been designed to solve the excessive consumption of energy, this will reduce the installed capacity of the uncontrolled excessive cooling inside some of the rooms. Overall, the building management system costs 337,904 SR with approximate payback period is 
5.4 years if implemented. Another recommended solution is to install an automatic door at the building's main entrance to keep the cooled air inside and so as not to increase the cooling load on the HVAC system. One of the important issues to be considered is raising the awareness of the personnel inside the building, whether they are students or faculty members, by using signs indicating how important this issue. These signs should emphasize the people inside the building to eliminate any source of wasting energy.

\section{Conflicts of Interest}

The authors declare no conflicts of interest regarding the publication of this paper.

\section{References}

[1] https://www.ceicdata.com/en/saudi-arabia/electricity-statistics/electricity-consumption

[2] https://www.se.com.sa/en-us/Pages/AnnualReports.aspx

[3] Abd-ur-Rehman, H.M., Al-Sulaiman, F.A., Mehmood, A., Shakir, S. and Umer, M. (2018) The Potential of Energy Savings and the Prospects of Cleaner Energy Production by Solar Energy Integration in the Residential Buildings of Saudi Arabia. Journal of Cleaner Production, 183, 1122-1130. https://doi.org/10.1016/j.jclepro.2018.02.187

[4] Vision 2030 (2016) Saudi Arabia's Vision for 2030. https://vision2030.gov.sa/en/media-center

[5] Shcherbak, V., Ganushchak-Yefimenko, L., Nifatova, O., Dudko, P., Savchuk, N. and Solonenchuk, I. (2019) Application of International Energy Efficiency Standards for Energy Auditing in a University Buildings. Global Journal of Environmental Science and Management, 5, 501-514.

[6] Alajmi, A. (2012) Energy Audit of an Educational Building in a Hot Summer Climate. Energy and Buildings, 47, 122-130.

https://doi.org/10.1016/j.enbuild.2011.11.033

[7] Corradoa, V., Ballarinia, I., Paduosa, S. and Tulipanoa, L. (2017) A New Procedure of Energy Audit and Cost Analysis for the Transformation of a School into a Nearly Zero-Energy Building. Energy Procedia, 140, 325-338. https://doi.org/10.1016/j.egypro.2017.11.146

[8] Lu, L., Zong, T., Zhang, L.H. and Sun, H.C. (2017) Energy Consumption Investigation and Data Analysis for One University of Guangzhou. Procedia Engineering, 205, 2118-2125. https://doi.org/10.1016/j.proeng.2017.10.135

[9] Magrinia, A., Gobbib, L. and d'Ambrosioc, F.R. (2016) Energy Audit of Public Buildings: The Energy Consumption of a University with Modern and Historical Buildings. Energy Procedia, 101, 169-175. https://doi.org/10.1016/j.egypro.2016.11.022

[10] Al Qdah, K. (2010) Potential Opportunities for Energy Savings in a Jordanian Poultry Company. Energy Conversion and Management Journal, 51, 1651-1655. https://doi.org/10.1016/j.enconman.2009.10.038

[11] Hassouneh, K.M., Al-Salaymeh, A. and Couscous, J.S. (2014) Energy Audit, an Approach to Apply the Concept of Green Building for a Building in Jordan. Sustainable Cities and Society, 14, 456-462. https://doi.org/10.1016/j.scs.2014.08.010

[12] Al-Widyan, M.I., Silliman, I.A., Alajlouni, A.A., Al Zu'bi, O.I. and Jaradat, A.I. (2018) Energy Performance Assessment of a Non-Domestic Service Building in Jor- 
dan. Jordan Journal of Mechanical and Industrial Engineering, 12, 69-75.

[13] Ahmed, F.A.M. (2017) Energy Audit in Educational Buildings Case Study of Fridhemsskolan in Gävle. Master Thesis.

[14] Al-Ghandoor, A. and Al-Hinti, I. (2007) Prospects of Energy Savings in the Jordanian Plastic Industry. Jordan Journal of Mechanical and Industrial Engineering, 1, 93-98.

[15] Hassouneh, K.M., Suleiman, S. and Al-Salaymeh, A. (2017) An Overview of Energy Savings Strategies at the University of Jordan Hospital. International Journal of Thermal \& Environmental Engineering, 14, 27-32.

[16] Cho, J., Moon, J., Rhee, K. and Kang, H. (2015) Energy Consumption Characteristics of Patient Room HVAC Systems for Large Hospital Buildings in Worldwide Climate Zones. Journal of the Architectural Institute of Korea, 31, 171-180. https://doi.org/10.5659/JAIK_PD.2015.31.3.171

[17] Cho, J., Moon, J. and Kang, H. (2017) Energy Performance Analysis for Energy Saving Potentials of a Hospital Building: A Case Study Methodology Based on Annual Energy Demand Profiles. Korean Journal of Air-Conditioning and Refrigeration Engineering, 29, 29-37. https://doi.org/10.6110/KJACR.2017.29.11.580

[18] Ma, H., Du, N., Yu, S., Lu, W., Zhang, Z., Deng, N. and Li, C. (2017) Analysis of Typical Public Building Energy Consumption in Northern China. Energy and Buildings, 136, 139-150. https://doi.org/10.1016/j.enbuild.2016.11.037

[19] Mujeebu, M.A. and Alshamrani, O.S. (2016) Prospects of Energy Conservation and Management in Buildings-The Saudi Arabian Scenario versus Global Trends. Renewable and Sustainable Energy Reviews, 58, 1647-1663. https://doi.org/10.1016/j.rser.2015.12.327

[20] EEMR (Energy Efficiency Market Report) (2015) International Energy Agency (IEA) Directorate of Sustainable Energy Policy and Technology.

http://www.iea.org/publications/freepublications

[21] Karati, M. (2011) Energy Audit in Building Systems, an Engineering Approach. 2nd Edition, CRC Press, Taylor and Francis Group, New York.

[22] Lighting Calculation. http://www.rapidtables.com/calc/light

[23] ASHRAE (2012) ASHRAE Handbook HVAC Applications.

[24] McQuiston, F.C., Parker, J.D. and Spitler, J.D. (2005) Heating, Ventilating and Air Conditioning Analysis and Design. 6th Edition, John Wiley and Sons, Hoboken. 